\title{
O mapa global de gestão
}

\section{Contributos para uma reflexão baseada nos modelos alemão e norueguês}

por Renato Lopes da Costa e Nelson António

RESUMO: A globalização dos mercados empresariais obriga a repensar as teorias de gestão existentes, exigindo-se mais do que nunca um mapa global mental aberto à diversidade cultural. Estudar os modelos de gestão e a sua interação nos domínios da cultura organizacional e as consequentes implicações na eficácia das organizações, é hoje mais do que nunca algo pertinente. É indispensável acompanhar os novos desenvolvimentos relacionados com os fenómenos de aprendizagem, de competência e, fundamentalmente, de conhecimento, não só prático e técnico, mas marcadamente diversificado sobre todas as outras culturas e mercados que nos constituem. Este artigo tem um caráter teórico e tem como objetivo expor uma linha de reflexão assente na forma cultural de fazer gestão e pensar a estratégia, a partir do estudo do modelo híbrido da Bundesland e do modelo social escandinavo.

Palavras-chave: Globalização; Mapa Global; Gestão; Cultura

\section{El mapa global de gestión Contribuciones a una reflexión basada en modelos alemanos y noruegos}

RESUMEN: La globalización de los mercados empresariales obliga a replantear las teorías de gestión existentes, exigiéndose más que nunca un mapa global mental abierto a la diversidad cultural. Estudiar los modelos de gestión y su interacción en los ámbitos de la cultura organizacional y sus consecuentes implicaciones en la eficacia de las organizaciones, es hoy más que nunca algo pertinente, en el sentido de contribuir con los nuevos avances relacionados en los fenómenos de aprendizaje, competencia y fundamentalmente conocimiento; y no sólo conocimiento práctico y técnico, sino un conocimiento notablemente diversificado sobre todas las demás culturas y mercados que nos constituyen. Este artículo tiene un carácter teórico y su objetivo es exponer una línea de reflexión basada en la forma cultural de hacer gestión y pensar la estrategia, a partir del estudio de modelo híbrido de Bundesland y del modelo social escandinavo.

Palabras clave: Globalización; Mapa Global; Gestión; Cultura 


\section{The global map of management Contributions to a reflection based on German and Norwegian models}

ABSTRACT: The globalization of corporate markets requires a rethinking of existing management theories, requiring more than ever a global mental map open to cultural diversity. Studying the management models and their interactions in the organizational culture domains and its consequences on the effectiveness of organizations is today more than ever relevant in order to be able to follow new developments related to the learning, competence and knowledge phenomena, and not just practical and technical knowledge, but a sharply diversified knowledge about all the other cultures and markets that constitute us. This article is of a theoretical nature and aims to expose a line of thought based on the cultural form of doing management and thinking strategy, from the study of the Bundesland hybrid model and the Scandinavian social model.

Key words: Globalization; Global Map; Management; Culture

\section{Renato Lopes da Costa} rjlca@iscte.pt

Doutorado em Gestão Geral, Estratégia e

Desenvolvimento Empresarial, ISCTE-IUL - Instituto Universitário de Lisboa. Professor Auxiliar e Diretor do MscBA, ISCTE-IUL, ISCTE Business School, Departamento de Marketing, Operações e Gestão Geral. Professor Coordenador e Diretor da licenciatura em Contabilidade e Administração, ISCAD, Instituto Superior de Ciências da Administração, Rua de São Paulo, n. ${ }^{\circ} 89,1200-427$ Lisboa, Portugal.

Doctorado en Dirección General de Estrategia y Desarrollo de Negocios, ISCTE-IUL Instituto Universitario de Lisboa. Profesor Auxiliar y Director de MscBA, ISCTE-IUL, ISCTE Business School, Departamento de Marketing, Operaciones y Gestión General. Profesor Coordinador y Director de la licenciatura en Contabilidad y Administración, ISCAD, Instituto Superior de Ciencia de la Administración, Rua de São Paulo, n. ${ }^{\circ} 89$, 1200-427 Lisboa, Portugal.

$\mathrm{PhD}$ on General Management, Strategy and

Entrepreneurship, ISCTE-IUL - University Institute of Lisbon. Professor, ISCTE-IUL, ISCTE Business School, Department of Marketing, Operations and General Management, MscBA Director, Master in Business

Administration. Full Professor, ISCAD-Lisbon, Accounting and Administration Degree Director,

Rua de São Paulo, n.o 89, 1200-427 Lisbon, Portugal.

\section{Nelson dos Santos António} nelson.antonio@iscte.pt

Doutorado em Gestão, Bergischen Universität, Alemanha. Professor Catedrático, ISCTE-IUL - Instituto Universitário de Lisboa, ISCTE Business School, Departamento de Marketing, Operações e Gestão Geral, Coordenador do Programa Doutoral em Gestão Geral, Estratégia e Desenvolvimento Empresarial e do Programa Doctor of Business Administration, 1649-026 Lisboa, Portugal.

Doctor en Administración, Bergischen Universität, Alemania. Profesor, ISCTE - IUL Instituto Universitario de Lisboa, ISCTE Business School, Departamento de Marketing, Operaciones y Gestión General, Coordinador del Programa de Doctorado en Dirección General de Estrategia y Desarrollo de Negocios y del Programa de Doctorado en Administración de Empresas, 1649-026 Lisboa, Portugal.

Dr. rerum. oec., Bergischen Universität, Germany. Full Professor, ISCTE-IUL - University Institute of Lisbon, ISCTE Business School. Professor, ISCTE-IUL, ISCTE. Business School, Department of Marketing, Operations and General Management, Director, PhD on General Management, Strategy and Entrepreneurship and Doctor of Business Administration, 1649-026 Lisbon, Portugal. 
Desde os seus primórdios, o objetivo da estratégia organizacional consiste no estudo das relações das organizações com o seu meio envolvente, numa perspetiva de longo prazo (António, 2006), mas a globalização da economia e o desenvolvimento das tecnologias de informação têm obrigado a repensar as teorias de gestão existentes. Os efeitos da economia num dado ponto do planeta manifestam-se hoje a milhares de quilómetros de distância, o que leva a que cada vez mais a gestão empresarial requeira maiores cuidados face à gestão dos negócios.

Hoje, mais do que nunca, estamos perante uma sociedade cada vez mais próxima, sendo o paradigma da deslocação dos gestores de um ponto para o outro do globo um lugar-comum no novo contexto internacional. Assim sendo, a mudança no contexto ambiental exige um mapa mental global, aberto à diversidade cultural, a conhecimentos sobre outras culturas e mercados e à integração de novos valores, sendo estes mais do que nunca os principais fatores críticos de sucesso para a gestão empresarial dos nossos dias.

A base teórica deste artigo tem como objetivo expor uma linha de reflexão assente na forma cultural de fazer gestão e pensar a estratégia, e procura exatamente explorar estes pressupostos, mostrando que o estudo das diferentes formas de gestão, do conhecimento cultural dos diferentes contextos e realidades internacionais e da capacidade de absorção de todo este conhecimento, deve ser a chave para o sucesso. O importante é conhecer o que se faz e como se faz nos «quatro cantos do mundo» e ter a disponibilidade mental para aprender e para perceber de que forma é gerido o conhecimento daí gerado, não só no sentido de garantir uma maior capacidade para competir, mas também para incorporar, ou, pelo menos, conhecer a forma como os outros agem, independentemente da sua localização, cultura, mercado ou valores.

Em suma, por mais que se possa projetar o futuro ou ir ao encontro das mudanças constantes ao nível do meio ambiente, as palavras «conhecimento» e «mapa global» devem ser as primeiras a constar nos dicionários das pessoas e das organizações, pois são hoje temas universais e o modo como os tratamos e ensinamos pode ser uma fonte de aprendizagem valiosa.

Apesar das inúmeras economias que fazem parte do nosso mapa global, e da existência de outras tantas que nos últimos tempos se têm tornado emergentes, é importante, no entanto, conhecer pormenorizadamente duas das mais importantes economias industriais da Europa, sendo que ambas são representativas de modelos distintos, ainda que ambos enraizados numa dinâmica social que os distingue da maior parte das economias que constituem o espaço europeu.

Este artigo está dividido em três partes. A primeira apresentará o modelo alemão e dará a conhecer a forma de gestão germânica numa dinâmica assente numa componente social que tem representado mais-valias para a sua atividade empresarial e que tem permitido consolidar vantagens compe-

\section{O importante é conhecer o que se faz e como se faz nos «quatro cantos do mundo" e ter a disponibilidade mental para aprender e para perceber de que forma é gerido o conhecimento daí gerado.}


titivas reais, sustentadas e duradouras para as organizações e para os próprios profissionais que trabalham nas mais diversas indústrias. A segunda parte apresentará uma retrospetiva histórica do modelo de gestão norueguês, com enfoque no seu quotidiano modelo pentangular alicerçado nas vertentes economia, cooperação, organização, adaptação e assistência social. No final serão apresentadas algumas considerações em resultado da leitura conclusiva destas duas orientações teóricas. No âmbito da comunidade empresarial não se pretende aqui apresentar uma fórmula mágica para gerir organizações, mas gerar reflexões e ideias que possam ajudar os gestores a melhor gerir as suas organizações do ponto de vista de governabilidade organizacional e gestão internacional. No que diz respeito à comunidade científica, este artigo visa explorar duas direções de pensamento estratégico que têm obtido considerável sucesso no nosso mapa global de governabilidade organizacional.

\section{O modelo de gestão alemão}

A Alemanha e a sua dinâmica industrial e empresarial sempre foram parte de uma parcela distinta de países que se constituíram como potências mundiais, sendo responsáveis também pelo crescimento e desenvolvimento de muitas economias do nosso mapa global. Neste aspeto, economistas, empresários, gestores e académicos são unânimes nas afirmações que tecem quanto à leitura da Alemanha, enquanto país único na forma como sempre se conseguiu reinventar, o que, entre outros aspetos, se foi devendo também à consistência de uma ideologia tipicamente social, que permitiu que o país detenha hoje em dia o segundo maior PIB per capita da Europa, logo a seguir à Holanda.

Ao estudarmos o modelo agente-principal, típico de países como os Estados Unidos, verificamos que o envolvimento dos stakeholders está longe de partilhar uma ideologia coletivista, estando mais ligado a uma forma de gerir onde a competitividade é a palavra de ordem. Nesta estrutura governativa, a agressividade pela partilha de mercados e lucros e a conflituosidade entre interesses pessoais e organizacionais redesenham um modelo que para muitos é errado, pois focaliza-se numa visão não sofisticada da empresa e pela exclusão de um paradigma de coletivismo e sinergias tão em foco à entrada deste novo século.

Mas, ainda que muitos países europeus, tais como Portugal, sejam também apologistas deste tipo de filosofias organizacionais, existem outros tantos que apresentam diferenças significativas ao nível da análise da sua estrutura governativa. Um desses modelos governativos, é apresentado pelo modelo europeu mais distinto, o alemão. Ao contrário do modelo anglo-americano, o modelo alemão (principalmente antes de 2003) enfatizava a necessidade da livre concorrência, onde se incluem aquisições hostis, e uma filosofia cooperativa, centrada sobre o conceito de codecisão (António, 2006). 
A visão sofisticada da organização empresarial apresentada pelo modelo alemão, considera, por isso, a empresa como um veículo social, envolvendo a sociedade empresarial como um todo, por forma a que a conjugação de forças e conhecimentos contribua para aquilo que António (2006) denomina como leitura do mapa global, definindo-o como algo amplo que vai muito para além do bem-estar dos acionistas.

Em termos sucintos, pode dizer-se que o modelo alemão descansa generalizadamente na monitorização contínua dos gestores pelos stakeholders, alicerçados em relações de longo prazo, cujo compromisso implícito gera, na maioria das vezes, aspetos importantes nas suas tomadas de decisão. O que gera a possibilidade de que sejam constituídos verdadeiros cartéis de acordos interfirmas que permitem a formação de compromissos, em desprimor de incentivos para venda de ações, assumindo neste contexto as pequenas e médias empresas (PME) não cotadas em bolsa um maior protagonismo em termos de importância na sua sociedade empresarial (ver Figura 1).

As caraterísticas apresentadas na Figura 1 foram as bases para que a Ale-

\section{A visão sofisticada da organização empresarial apresentada pelo modelo alemão, considera, por isso, a empresa como um veículo social, envolvendo a sociedade empresarial como um todo.}

Figura 1 Modelo de gestão germânico

- Desenvolvimento organizacional
com base na implementação das
tecnologias de informação de gestão
e qualificação dos seus recursos
humanos
- Responsabilidade social coletiva
na vertente ambiental

- Monitorização do desempenho empresarial realizado por todos os stakeholders

- Foco de preocupação quanto à formação e educação geral

- Custos operativos suportados também por determinados stakeholders (diluindo a visão anglo-americana em que o custo e o lucro são da inteira responsabilidade da empresa que compra o produto)

- Financiamento bancário e não pelo mercado bolsista
- Reconhecimento de relações grupais e associações de longoprazo

- Cooperação inventiva dos empregados

- Forte concentração da propriedade da empresa individual

- Reputação na qualidade das relações (ética) com fornecedores, clientes, empregados e restantes stakeholders

- Apoio de causas relacionadas com o terceiro mundo

- Correspondência próxima entre proprietários e gestores nas PME

- Condução pelo produto e não pelo mercado

- Gestão cooperativa e inovadora entre empresas

Fonte: Adaptado de António (2006) 
manha tenha sido descrita na década de 1980 e parte de 1990 como uma economia coordenada e uma referência, face à abordagem que teve em termos de parceria social nas suas relações industriais, sejam estas relativas a negociações salariais, esquemas corporativistas de formação profissional e/ou uma correta coordenação dos direitos dos trabalhadores. Regimes obrigatórios e abrangentes de segurança social são considerados nesta perspetiva como uma das principais caraterísticas do modelo alemão, que, apesar de algumas alterações nos últimos anos, caraterizou o país até 1997, ou mais precisamente até 2003, sobrepondo-se a defesa da força de trabalho às próprias perdas de receitas e/ou estatutos de que possam gozar determinadas classes profissionais.

O sistema político alemão caraterizou-se sempre como um sistema baseado em consensos, resultado de federalismos cooperativos, coligações governativas, caça ao voto legislativo e concentração do macrocorporativismo, que, em diversos momentos da sua história, conduziram à restrição de esforços para levar a cabo reformas políticas que se mostravam adequadas para fazer face aquilo que no mundo globalizado se ia gerando (Katzenstein, 1987; Czada, 2005). Historicamente, ainda que a mudança de base governativa se tivesse dado anos mais tarde, a década de 1990 (após a unificação das Repúblicas Federal e Democrática Alemã em 1989) veio dar início a um novo paradigma nos contextos social e económico alemão, com a implementação de algumas reformas estruturais que vieram de certa forma alterar a estrutura e os regulamentos empresariais e financeiros mantidos até então (Posen 2009), sobretudo em termos das medidas necessárias para melhorar a proteção legal dos acionistas, a liberalização do mercado de ações e a incorporação de ações inovadoras em termos empresariais.

Ainda que na década de 1990 tivessem sido registados alguns movimentos de transição, tais como os mencionados, na verdade as pressões para levar a cabo reformas financeiras mais profundas eram ainda bastante moderadas. Os políticos acreditavam que as receitas conseguidas em 1990 pela Alemanha Oriental ou antiga República Democrática, no valor de 500 mil milhões de marcos alemães contra os 108 mil milhões registados em 1989, iriam suportar e servir de almofada para a gestão dos custos da unificação, o que por si só se veio a mostrar insuficiente. Dois anos mais tarde, a balança de pagamentos alemã registava um défice de 150 mil milhões de marcos alemães, vendo-se o país e a banca forçados a prosseguir uma política de juros altos para atrair capital estrangeiro que pudesse financiar a sua economia (Czada e Hirashima, 2009).

É importante, no entanto, notar que durante este período o país gozava de conflitos políticos praticamente inexistentes. Era um período onde as políticas partidárias, assim como as relações federais se caraterizavam ainda por consensos generalizados e por um estado de bem-estar social, onde a formação e a reconversão profissional, a redução de horas de trabalho e a reforma antecipada serviam de base para restringir a oferta de trabalho, face 
às altas taxas de desemprego existentes na altura. Este foi assim o paradigma até 1997 (Czada, 2002, 2004, 2005).

Em 1997, o consenso social que remonta à década de 1950 foi posto em causa face à rejeição pelos sociais-democratas do projeto-lei de reformas e pensões apresentado pelo governo da CDU liderado pelo chanceler Helmut Kohl (Cerami, 2004; Czada e Hirashima, 2009).

Desde então, inúmeros conflitos foram surgindo em termos da continuação das políticas de bem-estar caraterísticas do modelo alemão anterior a este período. Tais conflitos agravaram-se face, principalmente, às circunstâncias económicas mundiais que conduziram a verdadeiros constrangimentos situacionais e à necessidade de se agir de forma pragmática (Cerami, 2004; Czada, 2005; Czada e Hirashima, 2009).

Estes constrangimentos em termos do bem-estar social tiveram verdadeiramente o seu início em 2003, período em que se iniciou um conjunto de reformas (propostas por uma comissão liderada por Peter Hartz, diretor de Pessoal da Volkswagen) estruturais no país, ao nível do mercado de trabalho, com o objetivo de evitar o colapso financeiro do sistema social, quer através da diminuição dos valores do fundo de desemprego, quer através do aumento da empregabilidade alicerçada no reforço da responsabilidade individual de cada cidadão (Czada, 2005; Buhr e Schmidt, 2007). Estes impulsos de reestruturação caraterizaram, assim, o princípio das reformas legislativas sem precedentes levadas a cabo pela Alemanha para promover o país como o centro financeiro da Europa (Czada e Hirashima, 2009).

Novos regulamentos sobre a bolsa de valores (participação mais transparente das empresas na bolsa de valores), restrições em termos do direito de voto dos bancos nas empresas por procuração (não assumindo automaticamente o direito de voto por terem mais de $5 \%$ do capital conseguido através de procurações), e abolição de impostos sobre ganhos de capital com a venda de participações acionistas (aumentando o nível de rivalidade entre diferentes grupos industriais), são apenas alguns exemplos daquele impulso (Lutz, 2000).

A este ciclo seguiu-se a crise profunda em que se viu mergulhada a Europa e o mundo em 2008, o que veio acentuar ainda mais a geração de conflitos que se desenvolveram desde 1997, resultando um conjunto de novas reformas institucionais e a abertura de novos caminhos na elaboração de políticas e iniciativas para levar a cabo estas mesmas reformas. Entre elas, ações para a promoção do mercado financeiro, a redução ainda mais acentuada do bem-estar social, e um conjunto de ações que conduziram a reduções drásticas em termos financeiros para equilibrar o orçamento do país (Czada e Hirashima, 2009).

Mas, ainda que estas reformas tenham de certa forma alterado aquilo que até 1997 caraterizava o modelo alemão, envolvendo a sociedade empresarial como um todo e a continuidade da estrutura governativa alemã e das suas empresas como veículo social, por si só não bastaram, o que veio a culminar na denominada Agenda 2010. 
O acentuado défice orçamental alemão e a perda de competitividade no cenário internacional obrigaram o chanceler Gerhard Schröder a implementar um pacote de reformas mais abrangente. O programa Agenda 2010 (assente numa orientação neoliberal dominante) implicou verdadeiras mudanças em termos tributários, de saúde pública, de previdência, de mercado de trabalho e de finanças municipais, além de ter lançado, também, o debate sobre a própria desregulamentação profissional.

Desde então o buraco entre a receita e a despesa pública alemã tem de facto diminuído consideravelmente, assim como a taxa de desemprego, caindo o número de desempregados de 5 para 3 milhões entre 2005 e 2009 (Czada e Hirashima, 2009), ainda que este resultado ficasse fundamentalmente ligado a uma diminuição da qualidade de vida dos cidadãos, a um aumento considerável do trabalho em part-time (que subiu de $11 \%$ para $17 \%$ em 2009) e a uma certa desvirtuação das diferentes realidades vividas entre as zonas este e oeste da sociedade alemã.

Ainda que estes resultados apontem para uma homogeneidade de desempenhos em termos políticos, sociais e económicos, na verdade desvirtuam um pouco a realidade. Embora a Alemanha esteja longe da heterogeneidade vivida pelo império alemão criado em 1871, pela República de Weimar a seguir à queda do Kaiser Guilherme II, ou mesmo pelo período anterior à unificação de 1989, a verdade é que historicamente a Alemanha sempre se caraterizou pela sua heterogeneidade.

Segundo Buhr e Schmidt (2007), em 2007, dos 13 milhões de alemães orientais (ex-República Democrática Alemã), 16,8\% estavam desempregados (1,3 milhões), enquanto a percentagem de desempregados na Alemanha ocidental (ex-República Federal Alemã), com um total de 65 milhões, era de apenas $8,4 \%$ (2,5 milhões), e, neste sentido, apesar dos anos terem diluído as amplitudes e desigualdades entre estas duas realidades, a verdade é que continuam a existir diferenças significativas em termos sociais e económicos, o que implica que a sociedade alemã não possa ser caraterizada como equitativa.

$\mathrm{Na}$ verdade, mais de duas décadas passadas após a queda do muro de Berlim subsistem ainda diferenças políticas, económicas e sociais, de cariz não equitativo, entre as zonas este e oeste alemãs. Este tipo de desigualdade é transcrita em algumas investigações, existindo na parte este a opinião generalizada de que o país não assenta numa base equitativa em termos sociais e económicos, e que o acesso à justiça e às oportunidades não é idêntico para todos os cidadãos (Czada e Hirashima, 2009).

No entanto, embora o ceticismo seja mais vincado a este, pelas razões mencionadas anteriormente, a verdade é que se tem assistido na Alemanha a uma generalizada e crescente deceção popular face às políticas sucessivas que têm sido levadas a cabo pelos seus governantes, o que tem conduzido a um sentimento de desencanto, que não só tem levado o eleitorado de direita a virar mais à esquerda, como à própria insatisfação da população face à democracia (Posen, 2009).
Mais de duas décadas passadas após a queda do muro de Berlim subsistem ainda diferenças políticas, económicas e sociais, de cariz não equitativo, entre as zonas este e oeste alemãs. Este tipo de desigualdade é transcrita em algumas investigações, existindo na parte este a opinião generalizada de que - país não assenta numa base equitativa em termos sociais e económicos, e que o acesso à justiça e às oportunidades não é idêntico para todos os cidadãos. 
A Alemanha optou por se apoiar numa estratégia de exportações fundamentalmente virada para dentro do espaço europeu (2/3), o que tornou a Alemanha menos sensível à turbulência dos mercados globais e menos vulnerável a mudanças e a fatores de competitividade entre nações e continentes. Apostou, também, nos mercados emergentes como a China, Rússia, Índia e África do Sul. A dependência da Alemanha face à economia norte-americana tem diminuído gradualmente. Ainda que esta situação possa variar de setor para setor ou em termos de produto (por exemplo, o setor do fabrico automóvel continua bastante dependente da economia norte-americana), a verdade é que as políticas governativas alemãs têm conduzido a sua estratégia de forma inteligente. O país continua a ser o «motor» europeu de referência em termos económicos, centrando-se sobretudo na especialização da indústria automóvel, engenharia industrial e construção e produtos químicos (Scharpt, 2003).

O que tudo isto nos indica, é que o modelo capitalista alemão, anteriormente caraterizado por uma sociedade empresarial sinérgica e por estruturas governativas e empresariais que funcionavam como veículo social, é hoje um modelo híbrido que tenta combinar as virtudes do modelo alemão anterior a 2003 e do modelo anglo-saxónico, caraterizado por um maior pragmatismo face às mudanças globais mundiais.

O modelo alemão atual é, deste modo, caraterizado pela tentativa de combinar equilíbrios sociais e flexibilidade económica, em termos de mercado financeiro e empresarial. A sua estratégia governativa está, por isso, ligada a reformas estruturais que servem como travão constitucional ao aumento do seu défice público que se cifrou em 2011 em 1,5\% do seu PIB e em 2014 numa percentagem já acima de zero (0,3\%), algo que já não acontecia desde 1969, com duas interrupções em 2000 (0,9\%) e 2007 (0,19\%). Em 2014, o país registou um nível recorde de receitas fiscais e de diminuição de custos, que contribuíram para a obtenção de um equilíbrio nas contas públicas que o próprio governo liderado por Angela Merkel só esperava para 2015. Excedentes orçamentais crescentes verificaram-se em 2015 (0,7\% do PIB) e 2016 (0,8\% do PIB).

\section{O modelo de gestão norueguês}

A Noruega, tal como hoje o conhecemos, tem uma longa história de mudanças de reinos governativos e esteve desde sempre ligada à sua pré-história viking sob controlo de Haroldo, cujo estilo de liderança da época (ano 872) levou a que muita da população emigrasse para a Islândia, Ilhas Faroé e Reino Unido, como forma de fugir à governação opressiva de então (Asheim e Isaksen, 1997).

Entretanto, a partir do Século X a mitologia tradicional viking foi lentamente substituída pela religião cristã, sendo mais tarde unificada numa junção dos três reinos constituídos pela Dinamarca, Noruega e Suécia, uma união sob a coroa da rainha Margarida (União de Kalmar). Mais tarde pela
O modelo capitalista

alemão, anteriormente

caraterizado por uma

sociedade empresarial

sinérgica e por estruturas

governativas

e empresariais

que funcionavam como

veículo social, é hoje

um modelo híbrido

que tenta combinar

as virtudes do modelo

alemão anterior a 2003

e do modelo

anglo-saxónico,

caraterizado por um

maior pragmatismo face

às mudanças globais

mundiais. 
união sob a mesma coroa da Noruega e Suécia, face à subordinação da Dinamarca a esta última como resultado das guerras napoleónicas da altura. Aquela unificação terminou pacificamente em 1905, dando lugar a dois estados independentes (Asheim e Isaksen, 1997).

Atualmente, a Noruega possui o segundo maior PIB per capita nominal do mundo (só ultrapassado pelo Luxemburgo), sendo o exemplo de uma economia cuja ênfase está diretamente ligada a um bem-estar social capitalista próspero, combinando um conjunto de atividades assentes no mercado livre com propriedade estatal em setores-chave, como petróleo, produção de energia hidroelétrica (sobretudo para consumo interno), produção de alumínio, banca e telecomunicações (Boschma e Martin, 2010).

A prosperidade mencionada é representativa de um padrão de vida muito elevado da sua sociedade, tendo sido considerada pela revista Foreign Policy, em 2009, como o país com melhor funcionamento e estabilidade do mundo, com riqueza acumulada, níveis de produtividade elevados e equidade. As diferenças salariais entre os trabalhadores de níveis hierárquicos mais baixos e os seus diretores executivos estão encurtadas ao mínimo, o atendimento público é completamente gratuito, as licenças de maternidade são de 12 meses, a taxa de desemprego não ultrapassa os 3\% da população ativa, o ensino superior é completamente subsidiado e há regimes abrangentes de segurança social. São números e indicadores que tornam esta economia incomparável a qualquer sociedade ocidental (Uyarra, 2010; Boschma e Martin, 2010).

Importa, no entanto, mencionar, que apesar de a Noruega ser o sétimo maior exportador do mundo de petróleo, representando esta componente cerca de 1/4 do PIB do país, o segredo do seu modelo passa fundamentalmente pela gestão criteriosa dos seus recursos, tentando potenciar ao máximo a exploração dos mesmos, ao nível do processamento de alimentos, construção naval, metais, produtos químicos, mineração, produtos de papel (floresta) e pesca. Na pesca, por exemplo, em 2006, conseguiu mesmo situar-se em valores absolutos como o segundo maior exportador de frutos do mar do mundo, logo a seguir à República Popular da China (Asheim e Mariusssen, 2010).

Estas são razões de sobra para que a permanência da Noruega dentro do contexto de uma Europa Única em termos formais fosse sempre rejeitada pelo país, declinada inclusive pelo povo em referendo por duas vezes. Apesar disso, o nível de responsabilidade norueguesa face à Europa nunca foi de todo negligenciado, sendo um membro altamente integrado no contexto europeu. Exemplo disso foi a sua adesão ao acordo de Schengen ou ao acordo do Espaço Económico Europeu que descreve os procedimentos e a execução das normas da União Europeia, que a Noruega transpôs para a sua lei interna através da EØS-loven. Isto tornou a Noruega um membro sem que esteja manietado por determinadas leis europeístas, deixando desde sempre claro que seria impossível setores-chave da sua economia, como os 
do petróleo, agricultura e pesca ficarem sujeitos à luz de qualquer tratado, pois são parte integrante da sua dinâmica económica. Podemos, assim, dizer que a autodeterminação e influência sobre o seu território são parte integrante do modelo de gestão económico norueguês, defendendo, enquanto país, ainda hoje as bases da sua história que nunca se deixou manietar por qualquer força externa (Arnold et al., 2005; Boas, 2007).

O caso da descoberta dos seus poços de petróleo já no Século XX e a correspondente administração deste recurso é um exemplo particular da gestão criteriosa dos seus recursos. Importa realçar, neste aspeto, que, ainda antes da descoberta do petróleo, a Noruega já possuía um elevado nível de desenvolvimento, pertencendo ao clube dos países mais ricos do mundo, assente num modelo de base económico, mas sobretudo social.

Governantes pelo mundo inteiro sustentam que será inviável conseguir obter os níveis de crescimento e desenvolvimento norueguês, pois não possuem os mesmos recursos naturais. Importa realçar neste contexto, a título de exemplo, que apenas $4 \%$ do dinheiro obtido com a venda do petróleo é injetado diretamente na sua economia, sendo o restante valor utilizado para financiar pensões sociais e manter a conservação do seu parque florestal (Rocha, 2010).

A forma idónea e responsável com que o país gere os seus recursos naturais e tenta manter elevados os níveis de equidade social da sua população podem ser considerados como dois dos importantes pilares do seu modelo de gestão. A título de exemplo, o nível de consciência ecológica dos noruegueses vai ao ponto de utilizarem carros maioritariamente de baixa cilindrada e outro tipo de meios de transporte alternativos para reduzirem ao máximo o consumo dos derivados de petróleo. Por outro lado, é de assinalar os níveis de igualdade social que o país conseguiu adquirir ao longo do Século XX, contrastando com o de outros países, também eles produtores de petróleo, que não se souberam modernizar e mantiveram as suas populações num nível de pobreza muito elevado.

Um exemplo paradigmático desta modernização social foi a construção de um país culturalmente alicerçado na procura pelo respeito das diferenças e numa base de diálogo e cooperação. Os estudos de Hofstede, em 2007 colocavam a Noruega como um dos países do mundo que se gere culturalmente numa base de médio e longo prazo, o que de facto é constatado em diversos outros estudos. Esta adaptação do país ao mercado global nem sempre foi fácil, sendo realizada por tentativa e erro, faseadamente, mas sempre pensada e planeada de forma cooperativa, envolvendo no processo o maior número de agentes sociais possíveis.

Toda esta caraterização cultural e social é depois transposta para o contexto mais particular do seu meio empresarial. Alguns estudos relacionados com o contexto empresarial norueguês, mostram também uma atmosfera de comunicação organizacional caraterizada pelo diálogo aberto, pelo apoio dado entre colegas e respeito mútuo. Aliás, estes fatores não são novos no
Ainda antes da descoberta do petróleo, a Noruega já possuía um elevado nível de desenvolvimento, pertencendo ao clube dos países mais ricos do mundo, assente num modelo de base económico, mas sobretudo social. 
contexto norueguês, sendo estas caraterísticas da sua cultura alimentadas desde 1970. Os estudos de Homans (1968) e de Johnson (1986) em países nórdicos, já na altura, mostravam, em vários contextos, uma forte relação entre estes indicadores numa perspetiva de melhoria das suas dinâmicas organizacionais.

De forma generalizada, produção, criação de valor e autossuficiência são componentes de um modelo norueguês de cariz pentangular alicerçado nas vertentes economia, cooperação, organização, adaptação e assistência social, constituído por consensos de base alargada entre parceiros sociais e centros de decisão política, a fim de manter uma base de coesão e qualidade institucional e de desenvolvimento progressivo do país (ver Figura 2).

Qualidade institucional neste contexto pode definir-se como a capacidade que um país detém ou pode deter relativamente à criação de políticas e serviços duradouros e independentes de mudanças de ordem política. O estudo de Thurber et al. (2011) é efetivamente ilustrativo deste contexto, realçando a capacidade da Noruega na construção do modelo de governabilidade distinto em termos de gestão dos seus recursos petrolíferos, separando questões políticas de regulação, de questões de ordem comercial, algo que perdura desde 1972 .

Neste caso específico e tipicamente norueguês, cabe à Companhia Nacional de Petróleo (CNP) a responsabilidade de promover as operações comerciais e ao Ministério do Petróleo e Energia estabelecer metas a cumprir pelo setor, assim como planear e supervisionar todo o processo de licenciamento que lhe está inerente. Compreende ainda um órgão regulador, cuja função é a de fornecer supervisão técnica, cobrar taxas aos operadores que realizam

Figura 2 Modelo de gestão norueguês

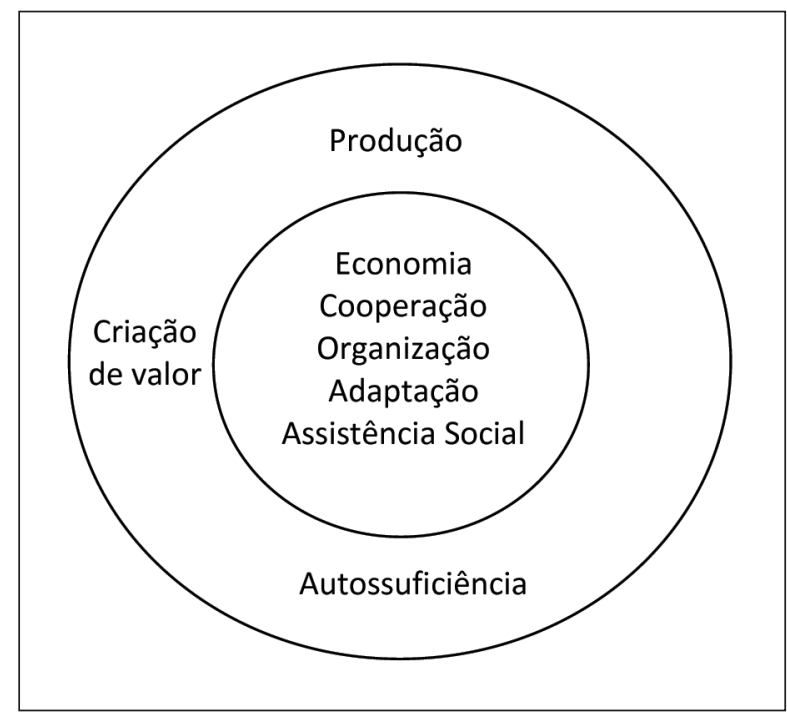

Fonte: Elaborado pelos autores 
as tarefas de extração do petróleo e definir normas relacionadas com a gestão destes recursos petrolíferos.

O relativo sucesso deste modelo na gestão dos recursos petrolíferos noruegueses é equacionado ainda hoje como hipótese a implementar noutros países, sobretudo face às diversas vantagens que daqui resultam. As vantagens são, por exemplo: concentração exclusiva da CNP em atividades comerciais para melhoria do desempenho operacional do setor, existência de um órgão regulador que permita maior autonomia governamental, diminuição da probabilidade de ocorrência de conflitos de interesses entre as partes (evitando, por exemplo, que a CNP possa usar os seus poderes para proveito próprio), e barreira face a eventuais atos de corrupção, dado o controlo existente por parte dos diferentes organismos que gerem o setor.

Outro aspeto particularmente interessante no contexto norueguês está relacionado com o seu processo adaptativo de aprendizagem. Um exemplo ilustrativo neste contexto esteve relacionado com as alterações realizadas pelo país, na última década, em termos das leis do trabalho, no sentido de desregulamentar o mercado, o que teve um forte impacto na estrutura de muitas indústrias. O processo foi acompanhado por mudanças imprevisíveis que causaram imensa turbulência na dinâmica económica, particularmente nas empresas do setor energético.

Como resposta, o setor empresarial norueguês adotou um processo adaptativo de aprendizagem faseado no tempo, alterando os seus centros de decisão para uma ótica centrada nos clientes, serviços, custos de produção e produtividade, e não tanto na procura por novas soluções técnicas. O focus da nova organização do trabalho passou para um aumento das exigências sobre os trabalhadores, especialização e flexibilidade (Aaseter, 2006), constituída, no entanto, uma vez mais, através de uma base alargada de consensos entre organizações do mundo laboral, associações empresariais e governo, fomentando o trabalho conjunto e cooperativo e uma política de corresponsabilidade, pilares caraterísticos em termos de ADN do seu modelo empresarial, económico e social.

O mesmo processo adaptativo de aprendizagem teve também reflexos na vertente social do país, existindo a necessidade, a partir da década de 1990, de redução de custos, um processo que teve particular impacto no setor da saúde, o que levou ao aumento da insatisfação por parte da classe médica, face à introdução de alterações que vieram degradar as suas condições de trabalho e diminuir consideravelmente a sua massa salarial (Victoria et al., 1997).

Uma vez mais o respeito mútuo e comunicação aberta entre as partes permitiu resolver esta questão sem grandes atritos, em defesa sobretudo da possibilidade de manutenção de um sistema de saúde abrangente e praticamente financiado na sua totalidade pelo Serviço Nacional de Saúde, que cobre de forma totalmente gratuita $95 \%$ de todo o sistema. 
Importa realçar que esta dinâmica comunicacional não é um aspeto particular no domínio da vertente social, é apenas parte de um todo composto por uma filosofia de comunicação à qual os noruegueses intitulam de «Ato de Planeamento e Construção», que valida uma ação participativa de todos os stakeholders num determinado negócio, na intervenção pública do governo sempre que se mostra necessária, na liberdade de expressão de proprietários em tomadas de decisão que tenham particular impacto na dinamização das suas estruturas industriais e empresariais e na participação ativa de todas as pessoas a nível municipal e concelhio. Aquele Ato serve como base de coordenação e de estabelecimento de compromissos entre as partes interessadas e envolvidas, a fim de se obterem consensos generalizados construídos a partir de opiniões divergentes e à partida conflituantes.

Apesar das sinergias que se procuram conseguir na Noruega, com o propósito de se estabelecer uma comunicação interpessoal não distorcida, justa e competente, e que permita simultaneamente que esta funcione como um importante input na vertente de aprendizagem social, não se pode, no entanto, afirmar, categoricamente, que tal aconteça sempre desta forma. Questões relativas a interesses particulares aparecem muitas vezes ligadas a determinado tipo de tomadas de decisão, sendo esta particularidade independente do contexto cultural que lhe esteja inerente. Ainda assim, é importante reter que o grau de abertura que aparece generalizadamente implícito no contexto cultural norueguês de gestão ajuda a explicar muito do seu sucesso enquanto país.

Outro dos importantes aspetos a realçar nos contextos empresarial e social norueguês, a fim de definir o seu modelo de gestão, é o domínio da liderança. Neste particular, de forma generalizada, o país segue um tipo de política, cujo líder, culturalmente, deve ser capaz de apoiar e motivar os colaboradores na prossecução dos objetivos que lhes estão inerentes. Este ponto tem especial relevância, face à não existência de qualquer problemática face à interação próxima entre líder e liderado, funcionando a interação e o feedback neste domínio como combustível para elevar os níveis de satisfação no trabalho e a produtividade. Aliás, a Noruega é reconhecidamente um país cujo clima de negócios se carateriza pela denominação PPP, i.e., elevada previsibilidade, produtividade e proficiência.

No caso norueguês, as questões de liderança têm uma relação recíproca onde líder e liderado agem interativamente em termos de olhares observatórios. Ao contrário das sociedades mais ocidentalizadas, os líderes no contexto norueguês não têm muito espaço para favoritismos ou para políticas comportamentais de cariz mais individualista, pois estão abrangidos num núcleo cultural empresarial homogeneizado.

A filosofia de liderança norueguesa segue, por isso, os pressupostos dos estudos observados por Bernstrøm et al. (2012), cujo confronto de ideias entre as partes é imerso no contexto de apoio social do líder e na relação profícua que este tenta estabelecer com as suas equipas. A denominação de
Importa realçar que esta dinâmica comunicacional não é um aspeto particular no domínio da vertente social, é apenas parte de um todo composto por uma filosofia de comunicação à qual os noruegueses intitulam de «Ato de Planeamento e Construção». 
conflito dá lugar neste pressuposto à terminologia "confrontação de ideias baseada na comunicação ativa», resultando desta relação win-win uma geração de ideias maioritariamente bem-sucedidas.

Ou seja, o que Bernstrøm et al. (2012) observaram nos seus estudos é que o stresse, a reduzida motivação, ou, até mesmo, o absentismo dão lugar neste domínio cultural a uma tendência clara do líder em adaptar o mais possível o trabalho às caraterísticas das equipas que lidera, sob um prisma de tolerância, compreensão e interação, funcionando os liderados neste pressuposto como agentes ativos na mudança das empresas.

\section{Considerações finais}

Como qualquer trabalho em progressão, este artigo não pretende mostrar que existe um modelo universal único de gestão, nem tão pouco deixar passar a mensagem de que exista uma estrutura única e eficiente que todas as empresas ou países devam imitar. Pretende ilustrar, a partir da sua caraterização de base teórica, que a gestão empresarial e a vertente cultural que lhe estão associadas terão sempre de ser analisadas como algo sistémico e que está em constante evolução, onde as empresas devem ser encorajadas a aprender umas com as outras, trocar experiências, pontos de vista e ideias, independentemente do país ou continente onde estas se localizem. Como em qualquer estrutura de conhecimento, o segredo estará sempre na adoção das melhores políticas e práticas em detrimento de outras que não pareçam tão adequadas.

Nesta medida, o conhecimento que se possa absorver a partir de outras culturas e mercados torna-se fulcral para a construção do mapa global mental dos nossos gestores, no que diz respeito ao desenvolvimento das suas organizações. Quer pela adoção das melhores políticas e modelos que possam adequar-se perfeitamente nas suas organizações, quer pela própria deslocação a que os gestores estão atualmente sujeitos face à economia e gestão globais, o novo paradigma exige, mais do que nunca, que se tenha de perceber o mundo como um todo, que se deva pensar a longo prazo e que exista uma responsabilização social coletiva relativamente a qualquer um dos stakeholders, sejam estes fornecedores, acionistas, clientes, empregados ou quaisquer outros.

Estamos perante um mundo que tem de ser pensado de forma complexa, onde lidar com os fenómenos da inovação, empreendedorismo, motivação, sinergias de trabalho entre colaboradores, envolvimento dos clientes, fornecedores e comunidade, constitui um aspeto que fica muito para além do que uma sociedade de livre circulação de capitais, bens e pessoas exige. Hoje, mais do que nunca, esta complexidade obriga a uma grande capacidade em integrar os melhores saberes existentes nas organizações a nível planetário. Todavia, para tal é necessário que se conheça e que se tenha informação sobre a forma como se faz a gestão e se pensa a estratégia nos quatro cantos do mundo. 
Deste modo, deverá delinear-se uma orientação teórica que possa permitir que se cultivem os gestores, os académicos e os próprios estudantes e que lhes permita compreender a forma como lutam e sobrevivem as empresas a nível global, pois, se assim não for, pode correr-se o risco de se ter pessoas a gerir em qualquer parte do mundo que não conhecem a competitividade que os rodeia, ou seja, a nossa realidade global. Este artigo teve assim o propósito de apresentar os modelos de duas das economias que ocupam as primeiras posições cimeiras em termos de PIB per capita europeu.

Num âmbito científico, é importante que se continuem a desenvolver estudos nesta mesma direção, em termos de pensamento estratégico, dando a conhecer a académicos e gestores empresariais os diferentes modos de agir, interagir e de pensar a estratégia. Futuras investigações de base teórica e empírica devem por isso ter como propósito comparar estes resultados com os de outros países, para que se possa ampliar o campo de visão nesta matéria. Do mesmo modo, será muito interessante estender este domínio a um conjunto de estudos que reflitam a caraterização dos modelos com dados de base quantitativa, para que se possam catalogar como casos de sucesso ou insucesso.

\section{Referências bibliográficas}

AASETRE, J. (2006), «Perceptions of communication in Norwegian forest management». Forest Policy and Economics, vol. 8(1), pp. 81-92.

ANTÓNIO, N. (2006), Estratégia Organizacional: Do Posicionamento ao Movimento. Edições Sílabo, 2. ${ }^{\text {a }}$ ed., Lisboa.

ARNOLD, E.; MUSCIO, A. e REID, A. (2005), «Mid-Term Evaluation of the VS2010 Programme: A Report to the Research Council of Norway. Conclusions and Recommendations from the Report to the Research Council of Norway». Technopolis. http://www.forskningsradet.no/servlet/Satellite?blobcol urldata\&blobheaderapplication\%2Fpdf\&blobheadername1ContentDisposition\%3A\&blobheadervaluelattachment\%3Bfilename\%3DConclusionsa ndRecommendations. pdf\&blobkeyid\&blobtableMungoBlobs\&blobwhere1274460337594\&ssbinarytrue. Acedido em abril de 2014.

ASHEINM, B. e ISAKSEN, A. (1997), «Location, aglomeration and innovation: Towards regional innovation systems in Norway?». European Planning Studies, 5, pp. 299-330.

ASHEIM, B. e MARIUSSSEN, A. (2010), «A política de inovação nórdica numa perspetiva comparativa». In Políticas de Inovação: Questões e Desafios, 51 77, Fagbokforlaget, Bergen.

BERNSTRØM, V. e KJEKSHUS, L. (2012), «Leading during change: the effects of leader behavior on sickness absence in a Norwegian health trust». BMC Public Health. Acedido em setembro de 2013.

BUHR, D. e SCHMIDT, J. (2007), «Big Reform with Little Effect? Labour Market and Employment Policy in Germany». CAP-Working Paper. Centrum für Angwandte Politikforschun, Munich.

BOAS, T. (2007), «Conceptualising continuity and change: The composite standard model of path dependence». Journal of Theoretical Political Science, 19, pp. 33-54.

BOSCHMA, R. e MARTIN, R. (2010), «The aims and scope of evolutionary economic geography». R. Boschma e R. Martin (Eds.), The Handbook of Evolutionary Economic Geography, 3.

CERAMI, A. (2004), «Germany after the unification: the exclusive society?». Paper no. 2004-001SC, University of Erfurt. 
81| Revista de GESTÃO dos Países de Língua Portuguesa

CZADA, R. (2002), «The German political economy in flux, in ten years of German Unification: Transfer, transformation, incorporation». In J. Leonhard e L. Funk (Eds.). Birmingham University Press, Birmingham, pp. 151-67.

CZADA, R. (2004), «The end of a model? Crisis and transformation of the German welfare state». University of Osnabruck, Working Paper no. 1/04. http://www.politik.uniosnabrueck.de/wp/WP\% 20104\%20Czada.pdf. Acedido em agosto de 2004.

CZADA, R. (2005), «Social policy: Crisis and transformation». In S. Green e W.E. Paterson (Eds.), Governance in Contemporary Germany: The Semi Sovereign State Revisited. Cambridge University Press, Cambridge, pp. 165-189.

CZADA, R. e HIRASHIMA, K. (2009), «Germany and Japan after 1989: Reform pressures and political system dynamics». ISS Research Series, vol. 33, pp. 75-90.

HOMANS, G. (1968), The Human Group. Routledge and Kegan Paul, London.

JOHNSON, J. (1986), «The Impact of the Workplace Social Support, Job Demands, and Work Control under Cardio-Vascular Disease in Sweden». Ph.D. Dissertation.

KATZENSTEIN, P. (1987), Politics and Policy in West Germany: The Grow of a SemiSovereign State. Temple Press, Philadelphia.

LUTZ, S. (2000), «From managed to market capitalism?». MPIfG Discussion Paper. Max Planck Institute für Gesellschaftsforschung, Köln.

POSEN, A. (2009), Reform and Grow in a Rich Country: German. Peterson Institute for International Economics, Washington.

ROCHA, M.A. (2010), «Modelos económicos e modelos sociais de desenvolvimento e de progresso social - a necessária conexão». http://expansao.sapo.ao/home/opiniao/Manuel_alves_da_rocha/modelos_economicos_e_modelos_sociais_de_desenvolvimento_e_de_prog resso_social_a_necessaria_conexao. Acedido em setembro de 2013.

SCHARPT, F. (2003), «Regieren im Europaischen Mehrebenensystem - Ansatze zu Einer Theorie». Leviathan, vol. 30, 1, pp. 65-92.

THURBER, M.; EMELIFE, I. e HELLER, P. (2010), «NPPC and Nigeria’s oil patronage ecosystem». Program on Energy and Sustainable Development, Working Paper, September 95. http://pesd.stanford.edu/publications/nnpc_and_nigerias_oil_patronage_ecosystems. Acedido em dezembro de 2010.

UYARRA, E. (2010), «What is evolutionary about 'regional systems of innovation'? Implications for regional policy». Journal of Evolutionary Economics, 20.

VICTORIA, A.; FALKUM, E.; HOFTVEDT, B. e AALAND, O. (1997), «The communication atmosphere between physician colleagues: Competitive perfectionism or supportive dialogue? A Norwegian study». Social Science \& Medicine, vol. 44, 4, pp. 519-526. 